LA - UR - 96 - 3554

September 1996

OEC 28093

$03 \mathrm{Tl}$

\title{
An Introduction to Enterprise Modeling and Simulation
}

James K. Ostic Collins E. Cannon

Technology Modeling and Analysis Group, TSA-7

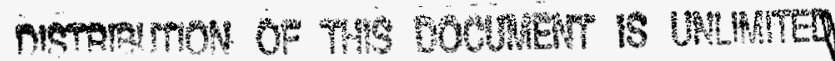
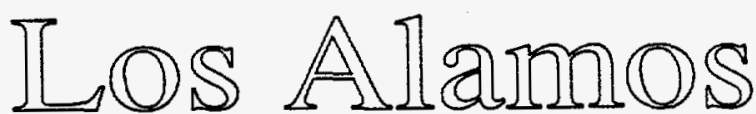

Los Alamos National Laboratory

Los Alamos, New Mexico 87545

Los Alamos National Laboratory is operated by the University of California for the United States Department of Energy under contract W - 7405 - ENG - 36 


\section{Table of Contents}

1. Introduction 1

2. Review of Enterprise Modeling and Simulation Methods 1

2.1 The Information System Perspective 2

2.2 The Business and Manufacturing Process Perspective 4

2.3 The Organizational Perspective 5

2.4 The Human Factors Perspective $\quad 7$

3. Use of Ontologies in Enterprise Modeling and Simulation 8

4. Enterprise Simulation Activities at Los Alamos 9

5. Glossary of Enterprise-Related Terms . 11

6. References 12 


\section{DISCLAIMER}

Portions of this document may be illegible in electronic image products. Images are produced from the best available original document. 


\section{DISCLAIMER}

This report was prepared as an account of work sponsored by an agency of the United States Government. Neither the United States Government nor any agency thereof, nor any of their employees, make any warranty, express or implied, or assumes any legal liability or responsibility for the accuracy, completeness, or usefulness of any information, apparatus, product, or process disclosed, or represents that its use would not infringe privately owned rights. Reference herein to any specific commercial product, process, or service by trade name, trademark, manufacturer, or otherwise does not necessarily constitute or imply its endorsement, recommendation, or favoring by the United States Government or any agency thereof. The views and opinions of authors expressed herein do not necessarily state or reflect those of the United States Government or any agency thereof. 


\section{Introduction}

As part of an ongoing effort to continuously improve productivity, quality, and efficiency of both industry and Department of Energy enterprises, Los Alamos National Laboratory is investigating various manufacturing and business enterprise simulation methods. A number of enterprise simulation software models are being developed to enable engineering analysis of enterprise activities.

In this document we define the scope of enterprise modeling and simulation efforts, and review recent work in enterprise simulation at Los Alamos National Laboratory as well as at other industrial, academic, and research institutions. References of enterprise modeling and simulation methods and a glossary of enterprise-related terms are provided.

\section{Review of Enterprise Modeling and Simulation Methods}

Generally, an enterprise is a unit of economic organization or activity. We further define an enterprise as "those activities that are required to develop and deliver products and/or services to a customer". Specifically, an enterprise then includes a number of functions and operations such as purchasing. manufacturing, marketing, finance, engineering, and research and development. The enterprise of interest are those corporate functions and operations necessary to manufacture current and potential future variants of a product.

The term "enterprise model" is used in industry to represent differing enterprise representations, with no real standardized definition. ${ }^{1}$ Due to the complexity of enterprise organizations, a vast number of differing enterprise modeling approaches have been pursued across industry and academia. ${ }^{2}$ Enterprise modeling constructs can focus upon manufacturing operations and/or business operations; however, a common thread in enterprise modeling is an inclusion of assessment of information technology. For example, the use of networked computers to trigger and receive replacement orders along a material supply chain is an example of how information technology is used to coordinate manufacturing operations within an enterprise.

An enterprise may be analyzed through the use of a mathematical or logical model representation. A flowchart of the processes necessary to manufacture and assemble a product is an example of a logical enterprise model. If a more dynamic representation is required, a simulation model is constructed, allowing the enterprise analyst to rapidly exercise a number of "what-if" scenarios using a computer program. Enterprise simulation analysts can focus their efforts in wide variety of disciplines, a sampling of which includes information technology, business and manufacturing process engineering, organizational framework analysis, and human resource utilization. The discussion which follows will summarize efforts underway in these areas to provide a review of the breadth of enterprise modeling and simulation methods in practice today. 


\subsection{The Information System Perspective}

One of the main thrusts of enterprise modeling concerns the organization and flow of information within an enterprise. Information is defined here as the data and knowledge produced and/or used by people, processes, and technology. It is of an extreme importance that the information used within an enterprise is accurate, timely, easily accessible, clear, complete, current, and relevant. Each enterprise depends upon a system of some kind which transfers, stores, and acts upon information. ${ }^{3}$ The design or architecture of this information system and its use can provide a competitive advantage to a firm as it competes within the marketplace.

Although there are various methods and techniques used to model an enterprise from an information system perspective, several basic elements are defined in the construction of the model. These basic elements are listed below.

- The critical information requirements of the system components

- The critical data sources residing within and outside of the enterprise

- The accuracy of the data flowing throughout the enterprise

- The various technologies used to store, disseminate, and access data throughout the enterprise

- The rate of information flows, including the time required to store, disseminate, access, assimilate, etc., data in the enterprise

- The costs incurred by the enterprise due to the information system, including costs due to information system maintenance, set-up, expansion, and normal use

The use of metrics in a model enables analysis of the information system. Properly defined metrics can be used to identify inefficiencies and faults. A simulation program based upon the information model provides opportunities to run "what if" scenarios to analyze possible changes without the costs and risks of their actual implementation. As each system is unique, the focus of an analysis may deal with issues unique to a certain system. However, some general issues to be addressed in an information system analysis are as follows.

- Does the present information system provide the necessary information for the enterprise to attain its goals?

- Does the information system in use allow for future growth and expansion?

- To what degree is the information system able to incorporate new technology, and at what effort and cost? 
- Are the different information structures in the information system compatible (i.e. databases)?

- Do elements of the information system exist that could be discarded without adversely affecting the enterprise?

- Could information flows be created or changed within the existing information system to benefit the enterprise?

- How would the change in the rate of flow of information affect the performance of the enterprise ${ }^{4}$

The following two statements capture the goals of enterprise analysis from an information system perspective.

1. What is the present design and state of the current information system and what is its effect on the enterprise?

2. Are there cost-effective changes that could be made to the present information system which would increase the efficiency and agility of the enterprise over the short run as well as over the long run?

The analysis of an information system can lead an enterprise to follow separate courses of action. The information system may be functioning at a satisfactory level and no action may be required. However, usually there are changes necessary to improve the existing "legacy" systems. Most enterprises fall into this category. It is also possible to completely redesign the information system and abandon the existing one. In reality this is generally not a plausible or cost-effective solution. Oftentimes, a considerable amount of capital and resources have been invested into the legacy system making such a drastic change unrealizable, expensive, and impractical. ${ }^{5}$

Several approaches to enterprise analysis from an information system perspective have been undertaken by various companies. IBM has developed CASE tools (Computer Aided Software Engineering) to model data flows and requirements across enterprise processes. The ISMOD (Information System Model and Architecture Generator) tool and other methodologies created at IBM have been used at over 450 companies over the past decade. Methodology to analyze information flow includes defining enterprise processes by interviewing key enterprise personnel and identifying enterprise functions, then placing this data into a five-tiered process hierarchy. Data flows between these processes are examined, evaluated, and then modeled. Metrics in the system, such as data sharing and data isolation ratios, allow IBM engineers to analyze the performance of the current system and make recommendations for present and future changes. ${ }^{4}$ 
Andersen Consulting provides information systems expertise for a variety of corporations. Andersen Consulting's approach entails analysis of the different systems in place, their compatibility, and the form and manner in which they treat data. Information requirements of resources and the primary systems in current use are catalogued to identify which systems are candidates for replacement. Alternative systems are evaluated and then the new system installed. Foci of the final system target enhanced data access, transfer, input, and storage. ${ }^{6}$

\subsection{The Business and Manufacturing Process Perspective}

Process modeling is concerned with analyzing the various processes and activities which occur in an enterprise to improve their capabilities and efficiency. A process can be defined as "a series of actions, changes, or functions that bring about an end or result". An enterprise then is a system consisting of various elements necessary to carry out processes. The performance of processes determine the level of success in the fulfillment of the enterprise's mission.

The objectives of enterprise modeling and simulation from a process engineering perspective are then:

- to benchmark and predict the performance of processes operating within the enterprise;

- to identify processes in the enterprise that are inefficient and cost in-effective (non-value added);

- to understand the leverage of process changes on the performance of the enterprise; and

- to carry out "what if" scenarios in order to evaluate proposed changes and improvements to the enterprise.

These objectives are captured within two general goals of process modeling:

1. to understand the design, behavior, strengths, inadequacies, and state of the existing enterprise from a process driven approach; and

2. to discard extraneous processes, improve the value added processes, and aid in the creation of new processes technologies in the enterprise in order to enable the fulfillment of its mission.

Process modeling of an enterprise includes the elements of entities, resources, activities, and controls. A simulation model is a dynamic rendering of these elements and their relationships with one another in the enterprise. Entities are what is processed by the enterprise. Entities could be information, customers, and manufactured products. The 
tasks to be performed by the enterprise are called activities. Activities are actions carried out by resources. Machining a part, packaging a product, and transporting an entity are examples of activities. Resources are the "who and what" which perform activities, such as personnel and equipment. Controls are the constraints imposed upon the system. Schedules, policies, capacities, priorities and plans are examples of controls. ${ }^{8}$

Elements defined in the enterprise are typically modeled using continuous or discrete event simulation software. Numerous modeling software packages have entered the market in recent years due to the interest and popularity of enterprise re-engineering. The recent advances of computer technology in recent years have allowed more comprehensive and user-friendly simulation packages to be developed and marketed. Oftentimes, extensive background and experience in programming are not prerequisites for successfully utilizing current software to model and analyze an enterprise. Most simulation packages allow the simulation analyst to easily define metrics, perform multiple "what if" scenarios, and graphically illustrate the behavior of the enterprise. Proper model definition and analysis assists the enterprise in optimizing production, manufacturing agility, and use of resources.

Examples of process modeling simulation in industry include discrete event applications. ProModel Corporation based in Orem, Utah has developed Windows-based software to simulate discrete event enterprise processes. MedModel, ServiceModel, and ProModel are three packages which enable an enterprise to model its current processes and proposed process changes. Graphical model development, built-in modeling constructs, cost analysis, and a data output package provide for user-friendly model construction and analysis.

Hewlett Packard has developed a process modeling enterprise simulation, which explores relationships between different factors and metrics used in manufacturing. Of particular focus in the model are levels of inventory and customer satisfaction. Analysis is concerned with product availability, forecasting quality, shipping performance, and materials planning, among others. This simulation tool is designed to evaluate what effects changing entity flow levels and process times have on the enterprise.'

\subsection{The Organizational Perspective}

Organizational modeling attempts to capture the designed behavior and framework of an enterprise to measure how this structure promotes and/or inhibits the enterprise's mission. Modern industrial enterprises are generally structured in a complex manner. Enterprise modeling may be used to understand current organization, identify unneeded bureaucracy and paperwork, make optimizing changes in enterprise structure, and indicate how to accommodate expansion.

An enterprise is structured so as to carry out its mission in an ordered and efficient manner. The design of the organizational framework must allow the enterprise to optimally pursue its strategy while conforming to external and internal constraints. An 
organizational modeling approach deals with resource management, decisional processes, and structure and location of organizations.

$\underline{\text { Roles and functions of critical resources in the enterprise }}$

An enterprise system performs processes to carry out its mission. Using an enterprise model, critical processes are mapped out and analyzed. The function of important resources in processes is defined, including attributes such as vital skills. Managers, engineers, executives, etc. all perform different processes within the enterprise and a result, each finds itself playing a different role in the organization. Modeling the critical processes, the resources which carry them out, the skills required, and logistics of the amount of work and resources available provides an opportunity to model "what if" scenarios. Such scenario analysis identifies proposed improvements to the current enterprise that can be analyzed with low potential risks. Cost in-effective use of resources can be identified leading to possible changes in resource utilization. The effects of enhancing resources' skills or abilities allowing for their broader use can be identified. The purpose of defining of new roles or consolidating several existing roles is to add value to certain processes. The model inevitably leads to better understanding of the various roles resources perform in the enterprise and assesses their value.

\section{Levels of responsibility and accountability of critical resources}

In order to remain competitive, performance and quality levels are assigned and maintained. Delegation of responsibility throughout the enterprise promotes adherence to enterprise standards and fulfillment of duties. Responsibilities of a resource should reflect the role the resource occupies in the enterprise. Accountability to higher authority promotes adherence to internal and external requirements. Defining and modeling the critical responsibilities of important resources within the enterprise enables the analyst to view and understand the chain of command "as is". Analysis identifies potential consolidation or further delegation of responsibilities making the enterprise more ordered and cohesive in its operations.

\section{Physical locations and allocations of enterprise resources}

Laws and customs of an area regulate the use and cost of maintaining and acquiring labor resources. Political stability, taxes, and tariffs entice or drive away enterprise activity. Cultural and environmental factors influence cost levels of shipping, maintenance, and procurement of resources and materials. The cohesiveness and responsiveness of the enterprise is affected by its proximity to other divisions and primary markets. Proper and accurate understanding of these conditions allow an enterprise to analyze the state of supply and market conditions.

\section{Decision-making processes within the enterprise}

For day-to-day activities to be carried out, decisions are made at every division and level in an enterprise. An enterprise model can be concerned with who makes critical decisions, 
what information is required, and the effects of those decisions on the enterprise. Mapping and analysis of the vital decision support systems of the enterprise reveal the leverage points within the enterprise where change is most likely to originate. Impact of high and low quality decisions may be illustrated and quantified. Extraneous and redundant information requirements can be identified and removed. Information inadequacies and shortcomings are exposed and "what if" solutions tested and analyzed. Assignments of decision making responsibilities are reviewed, resulting in their possible realignment and streamlining. In essence, the value of information is inferred from the decision-making process.

\section{Divisions or departments within the enterprise}

Resources, entities, and processes which share similar physical allocations, physical locations, responsibilities, attributes, etc. are naturally grouped together in divisions and departments within an enterprise. Departments and divisions in an enterprise are generally composed of resources, entities, and functions which share similar functions, attributes, and locations. These divisions are mapped in the organizational model, including the elements of which they are composed and the attributes they do and do not share. Metrics in the model are used to determine the level of cohesiveness and integration in the enterprise. Different divisional layouts may be created and tested with the model. Divisional overlaps, administrative gaps, and poor division location are brought to light by model analysis. Enterprise adjustments may entail breaking up a division(s) into multiple units, consolidating several divisions into one, creating new divisions from units of others, abolishing current divisions, adding or deleting units to divisions, or the changing of locations of divisions or the units they contain. ${ }^{3}$

In industry, a software prototype of model management systems, called SYMMS, provides for model sharing and integration to optimize organizational modeling and decision-making activities. The system also gives support for data management. In connection with SYMMS is a language called MDL which provides high-level, nonprocedural, textual capabilities to perform bottom-up and top-down hierarchical model construction. ${ }^{10}$

\subsection{The Human Factors Perspective}

Human factors deals primarily with the conditions of the human resources in the enterprise. Included factors are staffing requirements, skill requirements, safety requirements and conditions, and protection requirements. Such factors directly influence the productivity and job satisfaction of human resources. Such factors involving people occupy a unique place in an enterprise. Conditions in these areas may be defined and placed in a model to analyze the state of the enterprise and the people in it. Proposed changes may be evaluated using the model to reduce the risk of altering current conditions. 


\section{Use of Ontologies in Enterprise Modeling and Simulation}

Much attention has been given to the role of ontologies in enterprise modeling. In the classical sense, ontology is the branch of philosophy which deals with being. However, in the domain of enterprise architecture, an ontology is an outline or a schema used to structure objects, their attributes and relationships in a consistent manner. As in enterprise modeling, an ontology can be comprised of other ontologies. ${ }^{11}$

The purpose of ontologies in enterprise modeling is to formalize and establish the sharability, re-usability, assimilation and dissemination of information across all organizations and departments within an enterprise. Thus, an ontology enables integration of the various functions and processes which take place in an enterprise." Imagine a company meeting where nearly everybody speaks a different language. Marketing converses in pig Latin while research and development distributes a paper written in Sanskrit. The CEO gives her speech in English regarding the future plans and goals of the company but it is difficult to follow because she groups all of the nouns at the beginning of each sentence and all of the verbs together at the end. It is clear that such a company is in dire straits. Although this is a very extreme example, it brings to light some of the inherent the potential drawbacks of not using a consistent ontology. One common language with well articulated structure and vocabulary would enable the company to be more efficient in its operations.

A common ontology will allow for effective communication, understanding and thus coordination among the various divisions of an enterprise. These lead to more efficient production and flexibility within the enterprise. There are various kinds of ontologies used in numerous environments. While the language example given earlier dealt with the area of information systems and design, other ontologies may be defined for processes, methods, activities, etc., within an enterprise.

Using ontologies in enterprise modeling offers several advantages. Ontologies ensure clarity, consistency, and structure to a model. They promote efficient model definition and analysis. Generic enterprise ontologies allow for reusability of and automation of components. Because ontologies are schemata or outlines, their usefulness is amplified by the power of computer technology.

The use of ontologies does not ensure proper enterprise model definition, analysis, or clarity. Ontologies are limited by how they are defined and implemented. An ontology may or may not include the potential or capability to capture the all of the aspects of what is being modeled. Difficulties with how information is assimilated and disseminated could shift the focus of the model away from those aspects considered of importance to the enterprise. A model using ontologies is accurate to the level and breadth at which the ontologies are defined. The greater the flexibility and breadth of the ontology being used, the greater the detail and clarity of the resulting model. Thus, an ontology is a tool which can be used in enterprise modeling. But as any other tool, it is limited by the potential of its definition and design to accurately perform the task which is assigned to it. 
The TOVE (Toronto Virtual Enterprise) project at the University of Toronto, Industrial Engineering Department, provides a generic, reusable ontology for modeling enterprises. The ontology covers knowledge of activity, time, state, causality, activity-based costing, quality, and resources. The ontology is implemented by the use of $\mathrm{C}++$ computer code. TOVE uses an example of a lamp manufacturing plant modeled using ontologies and provides tools which allow simulation, visualization, and "what if" scenarios. ${ }^{11}$

\section{Enterprise Simulation Activities at Los Alamos}

At Los Alamos, we in the Technology Modeling and Analysis Group are focusing upon the process-based representation of the enterprise. In this view, the product is produced through a number of sequenced, yet independent, process steps. For example, the procurement of a raw material, the milling of a metal part, and the delivery of the product to the consumer are all examples of discrete process events which are required to manufacture a product.

Enterprise simulation is defined as a computer-based systems analysis of inter-company or intracompany business and technical activities. As identified above, the simulation includes processes necessary to develop, manufacture, and market a product. The ability of the enterprise to produce a competitive product is initially benchmarked with a set of product performance metrics (measures). These metrics generally include functionality, quality, time-to-market, and cost of the product. The enterprise simulation is then exercised to determine the impact of a change in a process, such as a change-out of a process technology. The leverage resulting from the use of advanced technologies and/or improved processes is then identified using the metric set. The role of rapidly evolving information technology is included in the simulation analysis.

The Technologies Enabling Agile Manufacturing (TEAM) program ${ }^{12}$ leverages the strengths of industry and government to improve industrial competitiveness through the pursuit of agility, or methods and organizations which facilitate changes in manufacturing systems and the delivered product. Los Alamos has developed an enterprise simulation model in support of this program to evaluate plant performance metrics in light of product and manufacturing process design. 13 Manufacturing operations were modeled within the Pratt \& Whitney facility in West Palm Beach, Florida. This enterprise simulation model is based upon a recursive executable cell concept which models individual processes as generic fundamental units within a hierarchical organizational structure. ${ }^{14}$ Figure 1 shows the recursive executable cell representation as it appears in the enterprise simulation model of the West Palm Beach facility.

In another enterprise simulation effort, a high-level computer simulation model of the United States Textile Industry was developed. 15 The ITEMS model was designed to analyze system dynamics behavior of the textile supply chain, including a fibers sector, a textile sector, an apparel sector, a retail sector, and dynamic customer demand. 


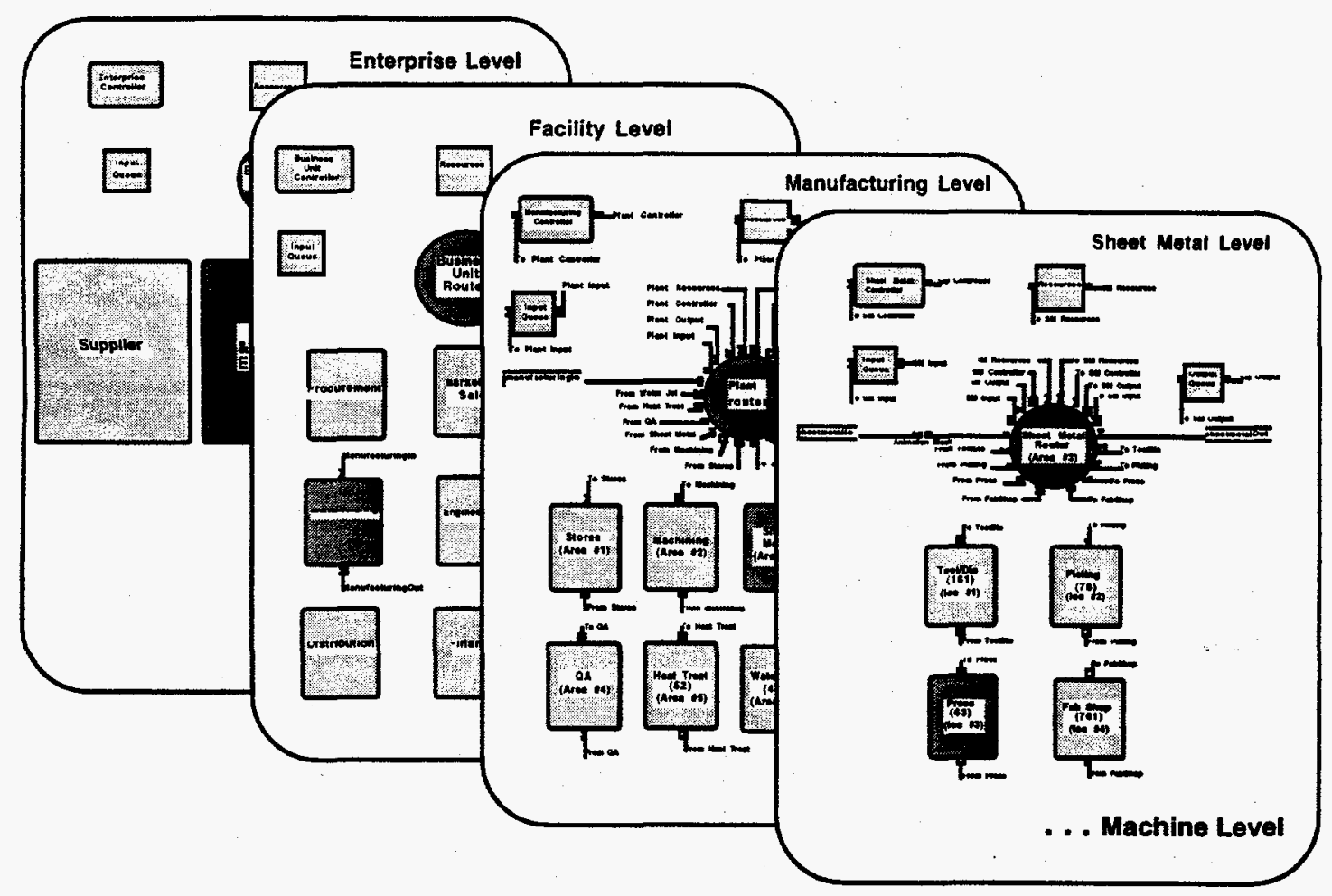

Figure 1. Enterprise Simulation Model of Pratt \& Whitney Facility

A recent effort at Los Alamos is to model the steel manufacturing enterprise using a hierarchical, object-oriented approach. ${ }^{16}$ Five separate levels of the enterprise are modeled, extending from the fundamental molecular level (a model of the molecules of steel formation) to the highest organizational level of the enterprise. 


\section{Glossary of Enterprise-Related Terms}

Activity-Based Costing - A procedure that allocates all costs (direct as well as indirect) to the activity of manufacturing.

Computer Integrated Manufacturing - The use of computers to design products, develop production plans, control manufacturing operations, and complete essential business activities.

Enterprise - Generally, a unit of economic organization or activity. Essential activities that are required to develop and deliver products and/or services to a customer.

Information Technology - Equipment, applications, and services used by organizations to deliver data, information, and knowledge.

Manufacturing Lead Time - The time from the commitment to manufacture a product to the time the product is acquired by a customer.

Model - In the context of enterprise modeling, a logical and/or mathematical representation of an enterprise.

Ontology - A generic schema or outline of a process, activity, or object.

Productivity - The quantity of product produced over a certain time period normalized by the resource(s) required.

Raw Materials Inventory - The quantity of input materials in storage necessary to support continued manufacturing operations.

Resources- Reusable and non-reusable entities (equipment, labor, information, materials) which are required to complete an enterprise-related task.

Simulation - A numerical exercise of a model to determine the impact of various inputs on the corresponding predictive outputs. 


\section{References}

1 E. Aranow, "Modeling Exercises Shape Up Enterprises", Software Magazine; Vol. 11 (1991), p. 36-43.

2 C. J. Petrie Jr., "Introduction", Enterprise Integration Modeling - Proceedings of the First International Conference, 1992 (MIT Press), p. 563.

$3 \quad$ M. A. Rood, "Enterprise Architecture: Definition, Content, and Utility", Proceedings of the 3rd Workshop on Enabling Technologies: Infrastructure for Collaborative Technologies, 1994, p. 106-111.

4 R. L. Katz, "Business/Enterprise Modeling”, IBM Systems Journal 29, 509-523 (1990).

5 J. H. Sheridan, "Enterprise Integration: The Next Plateau", Industry Week; June 20, 1994, p.30-38.

6 A. Petras and S. Eppolito, "Information Systems: An Information Tour", Transmission and Distribution World; Vol 46 (1994), p. 47-50.

7 C. Bussler and S. Jablonski, "An Approach to Integrate Workflow Modeling and Organizational Modeling", Proceedings of the 3rd Workshop on Enabling Technologies: Infrastructure for Collaborative Technologies, 1994, p.81-95.

8 C. Harrel and K. Tumay, Simulation Made Easy, Industrial Engineering and Management Press, copyright 1995, p.17-20.

9 M. S. Mujtaba, "Enterprise Modeling and Simulation: Complex Dynamic Behavior of a Simple Model of Manufacturing", Hewlett-Packard Journal 45, 80112 (1994).

10 W. Muhanna, European Journal of Operational Research, 1994, p.214-242.

11 G. Fadel, M. Fox, M. Gruninger, "A Generic Enterprise Resource Ontology", Proceedings of the 3rd Workshop on Enabling Technologies:Infrastructure for Collaborative Enterprises, 1994, p.117-128.

12 "Technologies Enabling Agile Manufacturing Strategic Plan-Revision 2.3", TEAM Program Office, Oak Ridge National Laboratory, (1995).

13 J. Ostic, J. Gonzales, P. Reardon, and S. Painter, "Enterprise Simulation Technology Enabling Agile Manufacturing", Report No. LA-UR-95-3174 (1995). 
14 P. Tag, J. Ostic, S. Painter, and P. Reardon, "The Recursive Executable Cell: A Generic Architecture for Enterprise Modeling Simulations Using Extend", Report No. LA-UR-69-695 (1996).

15 P. Tag, "ITEMS: A Systems Dynamics Enterprise Model of the Integrated U.S. Textile Complex - DRAFT”, (1996).

16 A. Henricksen, "A Framework for Hierarchical, Object-Oriented Simulation Modeling of a Steel Manufacturing Enterprise", San Diego, California, 1996. 